\title{
A Study of the Optimum Pore Structure for Mercury Vapor Adsorption
}

\author{
Byung-Joo Kim, Kyong-Min Bae, ${ }^{\dagger}$ and Soo-Jin Park ${ }^{\dagger, *}$ \\ Smart Composite Material Research Team, Carbon Valley R\&D Division, Jeonju Institute of Machinery and Carbon Composites, \\ Jeonju 561-844, Korea \\ ${ }^{\dagger}$ Department of Chemistry, Inha University, Incheon 402-751, Korea. ${ }^{*}$ E-mail: sjpark@inha.ac.kr \\ Received November 24, 2010, Accepted March 3, 2011
}

\begin{abstract}
In this study, mercury vapor adsorption behaviors for some kinds of porous materials having various pore structures were investigated. The specific surface area and pore structures were studied by BET and D-R plot methods from $\mathrm{N}_{2} / 77 \mathrm{~K}$ adsorption isotherms. It was found that the micropore materials (activated carbons, ACs) showed the highest mercury adsorption capacity. In a comparative study of mesoporous materials (SBA15 and MCM-41), the adsorption capacity of the SBA-15 was higher than that of MCM-41. From the pore structure analysis, it was found that SBA-15 has a higher micropore fraction compared to MCM-41. This result indicates that the mercury vapor adsorptions can be determined by two factors. The first factor is the specific surface area of the adsorbent, and the second is the micropore fraction when the specific surface areas of the adsorbent are similar.
\end{abstract}

Key Words : Mercury vapor adsorption, Activated carbon, SBA-15, MCM-41, Optimal pore structure

\section{Introduction}

All over the world, coal is a major energy resource which is mainly burnt to produce electricity. As far as we know, it is not a clean fuel. Various types of pollutants, such as $\mathrm{SO}_{\mathrm{x}}$, $\mathrm{NO}_{\mathrm{x}}$ and mercury, are released into the atmosphere while burning coal. Mercury emissions have attracted an increasing amount of concern due to the high toxicity, volatility, bioaccumulation in the environment and neurological health impacts of mercury. According to the Global Mercury Assessment Report, coal-fired power plants are the primary source of anthropogenic emissions of mercury into the atmosphere. ${ }^{1-4}$

Because MCM-41 and SBA-15 materials exhibit uniform mesopores with near-cylindrical shapes, they have been used as model adsorbents for the verification, improvement and/ or development of characterization methods. Thus far, MCM-41 materials have been used mostly for the verification and improvement of the applicability of classical methods of pore size analyses. In contrast, large-pore materials such as SBA-15 have not found adequate utility for this type of investigation because SBA-15 contains complementary small pores in its mesopore walls, which makes independent assessments of the pore diameter in these materials more difficult. ${ }^{5-8}$

The adsorption behaviors of an adsorbent can be controlled by its specific surface area and pore structure, as reported in several works. ${ }^{9-12}$ It is well accepted that MCM-41 and SBA-15 are potential adsorbents for elemental mercury vapor in an air stream. However, the effects of their pore structures on mercury adsorption have not been exhaustively studied.

In this work, the mercury adsorption behaviors of the porous materials of activated carbons, SBA-15, and MCM-
41 are observed. In addition, the relationship between their pore structures and the adsorption capacity for mercury are also investigated.

\section{Experimental Section}

Sample Preparation. ACs supplied from Hanil Green Tech Co. of Korea $(8 \times 16$ meshes $)$ were used in this work. Prior to use, impurities in the ACs were removed via Soxhlet extraction by boiling with acetone at $80{ }^{\circ} \mathrm{C}$ for $2 \mathrm{~h}$. The ACs were then washed several times with distilled water and dried in a vacuum oven at $85^{\circ} \mathrm{C}$ for $24 \mathrm{~h}$.

For the synthesis of SBA-15, $2 \mathrm{~g}$ of triblock copolymer P123 was dissolved in $75 \mathrm{~mL}$ of $1.6 \mathrm{~mol} / \mathrm{L} \mathrm{HCl}$. A set amount of pore-expanding agent was added according to the designed size of the pore and the resulting solution was heated to $37-40{ }^{\circ} \mathrm{C}$ under vigorous stirring. After $2-3 \mathrm{~h}, 4.5$ $\mathrm{mL}$ of tetraethoxysilane was added and this was stirred for $24 \mathrm{~h}$. Subsequently, $23 \mathrm{mg}$ of ammonium fluoride in water $(2.5 \mathrm{~mL})$ was added to the solution, which was then transferred to an autoclave for aging at $100{ }^{\circ} \mathrm{C}$ for $30 \mathrm{~h}$. The resulting precipitate was filtered, washed with water and ethanol, and dried. The white powder obtained was calcined at $550{ }^{\circ} \mathrm{C}$ in air for $6 \mathrm{~h}$.

To prepare MCM-41, hydrothermal synthesis was conducted following a procedure described in the literature. ${ }^{13,14}$ A clear solution of sodium silicate with a $\mathrm{Na} / \mathrm{Si}$ ratio of 0.5 was prepared by the admixing of $46.9 \mathrm{~g}$ of $1.00 \mathrm{M}$ aqueous $\mathrm{NaOH}$ solution and $14.3 \mathrm{~g}$ of colloidal silica (LUDOXHS40, $40 \mathrm{wt} \%$ suspension in water, Aldrich Co.) as the silica source. The mixture was then heated under stirring at $353 \mathrm{~K}$ for $2 \mathrm{~h}$. The sodium silicate solution was added dropwise to a round-bottle flask containing a mixture of $0.29 \mathrm{~g}$ of 28 wt $\%$ aqueous $\mathrm{NH}_{3}$ solution and $20.0 \mathrm{~g}$ of CTMACl solution 


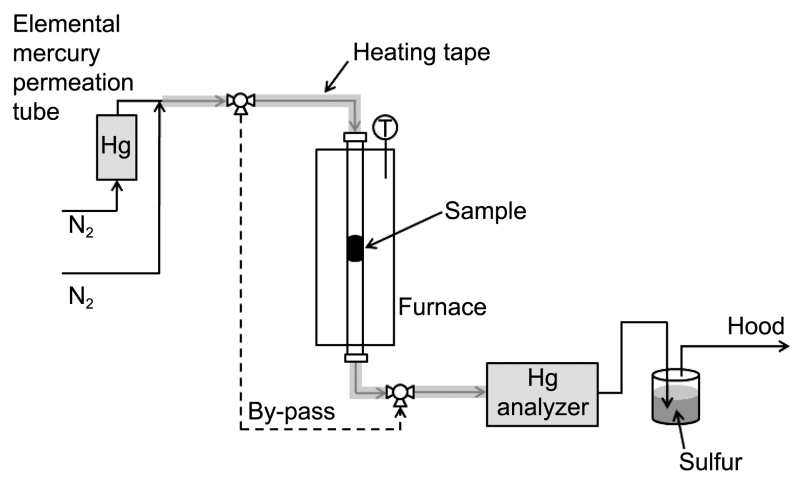

Figure 1. A schematic diagram of the mercury vapor adsorption apparatus.

(cetyltrimethylammonium chloride, $25 \mathrm{wt} \%$ solution in water, Aldrich Co.), with vigorous mechanical stirring at 298 $\mathrm{K}$ for $1 \mathrm{~h}$. The final mixture was heated to $373 \mathrm{~K}$ while maintaining the $\mathrm{pH}$ adjustment at 10.2 for 4 days. Finally, the precipitated solid was filtered off, washed extensively with deionized water, air-dried, and calcined in air at $823 \mathrm{~K}$ for $10 \mathrm{~h}$. The pure silica MCM-41 was denoted as MCM- 41 .

Characterization. Small-angle XRD patterns of the copper/activated carbon hybrid materials as a function of the plating time were obtained by Rigaku model MAX 2200v diffraction meter with $\mathrm{CuK}_{\alpha}$ radiation $(\lambda=0.15418 \mathrm{~nm})$.

Nitrogen adsorption isotherms at $77 \mathrm{~K}$ were measured using a Belsorp Max (BEL Japan). Prior to each analysis, the samples were degassed at $573 \mathrm{~K}$ for $9 \mathrm{~h}$ to obtain a residual pressure of less than $10^{-5}$ Torr. The amount of nitrogen adsorbed onto the samples was used to calculate the specific surface area by means of the BET equation. ${ }^{15,16}$ The total pore volume was estimated to be the liquid volume of nitrogen at a relative pressure of about 0.995 . The micropore volume was calculated using the Dubinin-Radushkevich (DR) equation. ${ }^{17}$

A schematic diagram of the elemental mercury adsorption apparatus is shown in Figure 1. A quartz sample cell (diameter: $12.7 \mathrm{~mm}$ ) was placed inside a temperature-controllable tubular furnace at a temperature of $70{ }^{\circ} \mathrm{C}$. For every experiment, $1.0 \mathrm{~g}$ of samples were loaded and packed inside the quartz tube. A carrier gas was fed into the adsorption apparatus at a flow rate of $100 \mathrm{~mL} / \mathrm{min}$. Elemental mercury gas was generated from elemental mercury permeation tubes (Dynacalibrator ${ }^{\circledR}$ Model 150, VICI Metronics Inc., USA), and the concentration of the elemental mercury gas was maintained at $800 \mu \mathrm{g} / \mathrm{m}^{3}$ during the experimental process. Measurement of both the inlet and outlet concentration of the elemental mercury was done using a mercury analyzer (VM-3000, Mercury Instruments, Germany), and sulfur was used to capture the elemental mercury from the effluent gas.

\section{Results and Discussion}

Structural Properties of SBA-15 and MCM-41. Figure 2 shows the small-angle XRD diffraction patterns of SBA15 and MCM-41. The SBA-15 shows three well-resolved

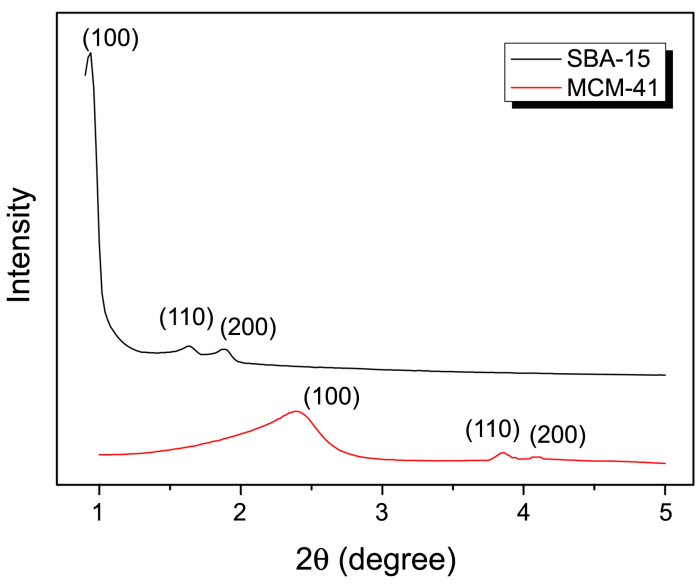

Figure 2. XRD patterns of SBA-15 and MCM-41.

peaks. The intense peak in the 2-theta range of $1^{\circ}$ corresponds to the (100). The weak peaks in the 2-theta range of $1.6^{\circ}$ to $1.8^{\circ}$ correspond to the (110) and (200). In addition, the MCM-41 exhibits an intense peak in the 2-theta of 2.4 due to (100) reflection as well as small peaks due to (110) and (200) reflections. The XRD patterns reveal that the synthesized SBA-15 and MCM-41 have a high degree of hexagonal mesoscopic organization. ${ }^{18,19}$

Textural Properties. An understanding of the porosity and specific surface area of an adsorbent can be achieved by the construction of an adsorption isotherm of $\mathrm{N}_{2}$. The $\mathrm{N}_{2}$ adsorption isotherms of the ACs, SBA-15, and MCM-41 are shown in Figure 3. The ACs is a Type I isotherm according to the BET classification, showing well-developed micropores. ${ }^{15}$ It is evident that most of the pore volume of the samples was filled below a relative pressure of about 0.1 , indicating their high microporosity. After a sharp increase in the relative pressure to 0.1 , the isotherms showed only very small increases in the pore volume, with no further adsorption. The isotherm types of SBA-15 and MCM-41 are Type IV, which is typical for mesoporous materials that exhibit capillary condensation and evaporation and that have large pore sizes with narrow size distributions. ${ }^{20}$ This is identified as a slow rate of increase in $\mathrm{N}_{2}$ uptake at a low

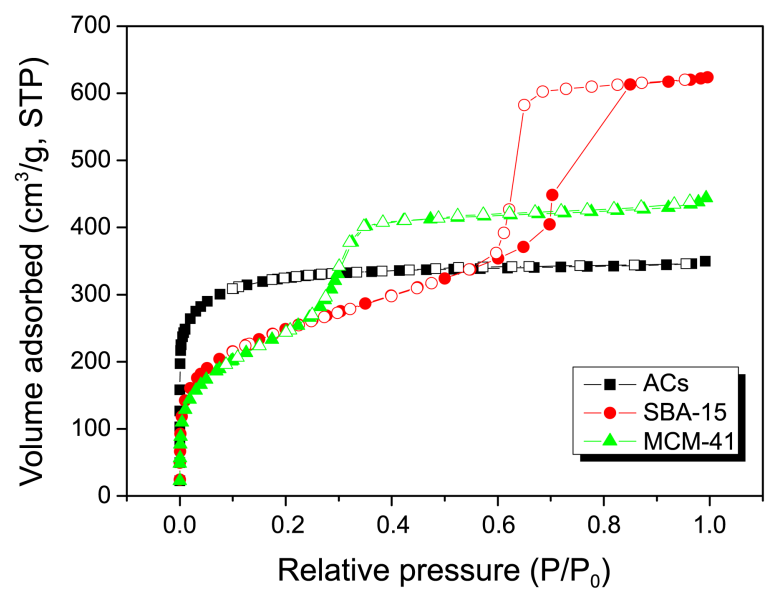

Figure 3. Nitrogen adsorption isotherms of ACs, SBA-15 and MCM-41. 
Table 1. Textural properties of porous materials

\begin{tabular}{lccc}
\hline & ACs & SBA-15 & MCM-41 \\
\hline Specific surface area $\left(\mathrm{m}^{2} / \mathrm{g}\right)$ & 1195 & 894 & 893 \\
Micropore surface $a r e a\left(\mathrm{~m}^{2} / \mathrm{g}\right)$ & 1103 & 166 & 119 \\
Total pore volume $\left(\mathrm{cm}^{3} / \mathrm{g}\right)$ & 0.541 & 0.963 & 0.685 \\
Micropore volume $\left(\mathrm{cm}^{3} / \mathrm{g}\right)$ & 0.463 & 0.179 & 0.091 \\
Fraction of micropore $(\%)$ & 85.6 & 18.6 & 13.3 \\
Mesopore volume $\left(\mathrm{cm}^{3} / \mathrm{g}\right)$ & 0.078 & 0.784 & 0.594 \\
Micro-/Mesopore ratio & 5.936 & 0.228 & 0.153 \\
Average pore diameter $(\mathrm{nm})$ & 1.809 & 4.311 & 3.066 \\
\hline
\end{tabular}

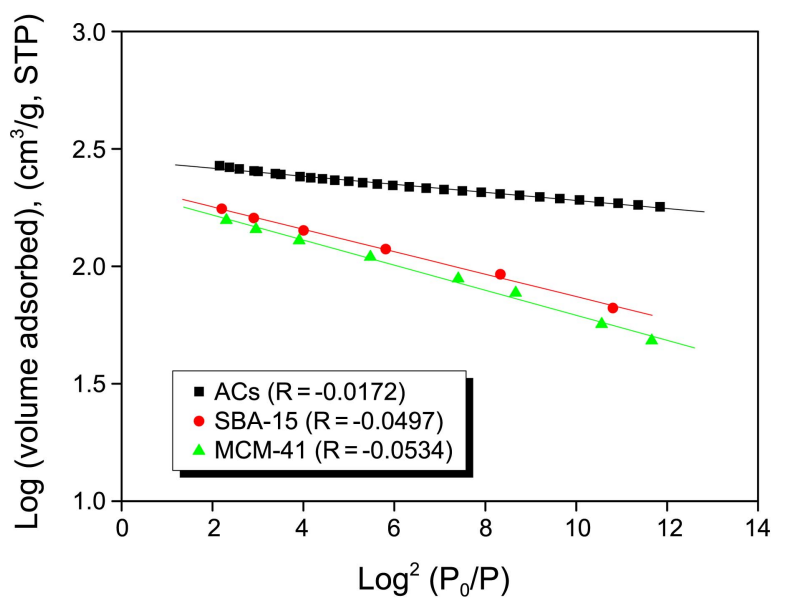

Figure 4. D-R plots for $\mathrm{N}_{2}$ at $77 \mathrm{~K}$ of ACs, SBA-15 and MCM-41.

relative pressure, corresponding to monolayer-multilayer adsorption on the pore walls.

Table 1 shows the detailed information of the textural properties of the samples from the $\mathrm{N}_{2} / 77 \mathrm{~K}$ adsorption isotherms. The ACs had a high specific surface area and micropore volume because they are micropore materials. The mesoporous materials SBA-15 and MCM-41 showed a low specific surface area and micropore volume; thus, the micropore volume of SBA-15 is higher than that of MCM41.

Figure 4 shows the micropore volume of all samples represented by D-R plots. This can be calculated by Eq. (1). ${ }^{17,21}$

$$
\log \mathrm{W}=\log \mathrm{W}_{0}-\mathrm{B}(\mathrm{T} / \mathrm{\beta})^{2} \log ^{2}\left(\mathrm{P}_{0} / \mathrm{P}\right)
$$

Here, $\mathrm{W}$ is the adsorption volume according to $\mathrm{P} / \mathrm{P}_{0}, \mathrm{~W}_{0}$ is the micropore volume, $\mathrm{B}$ is the structural constant, $\beta$ is the affinity coefficient, and $\mathrm{T}$ is the temperature.

Pores within porous materials were classified as micropores $(<2 \mathrm{~nm})$, mesopores $(2-50 \mathrm{~nm})$, and macropores $(>50$ $\mathrm{nm})$, in accordance with the classification adopted by the IUPAC. ${ }^{22}$ Figures 5 and 6 display the pore size distributions of the ACs, SBA-15 and MCM-41. The ACs exhibited distinct abruption in the $\mathrm{P} / \mathrm{P}_{0}$ range from 0.5 to $0.8 \mathrm{~nm}$, showing that this sample has a uniform pore size distribution. The pore size distributions of SBA-15 and MCM-41 are wide, ranging from 5 to 15 and 2.5 to $3.4 \mathrm{~nm}$, respectively. As a result, it was found that the $\mathrm{AC}$ has a micropore structure

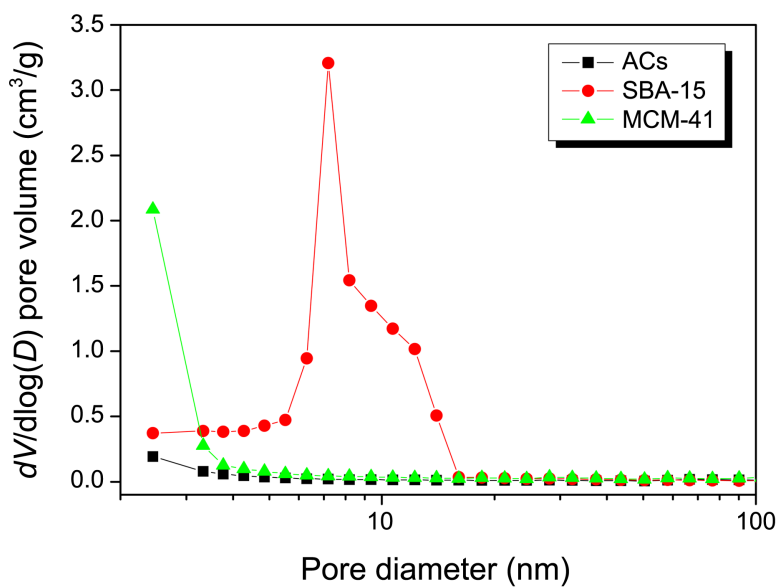

Figure 5. BJH pore size distribution of ACs, SBA-15 and MCM41.
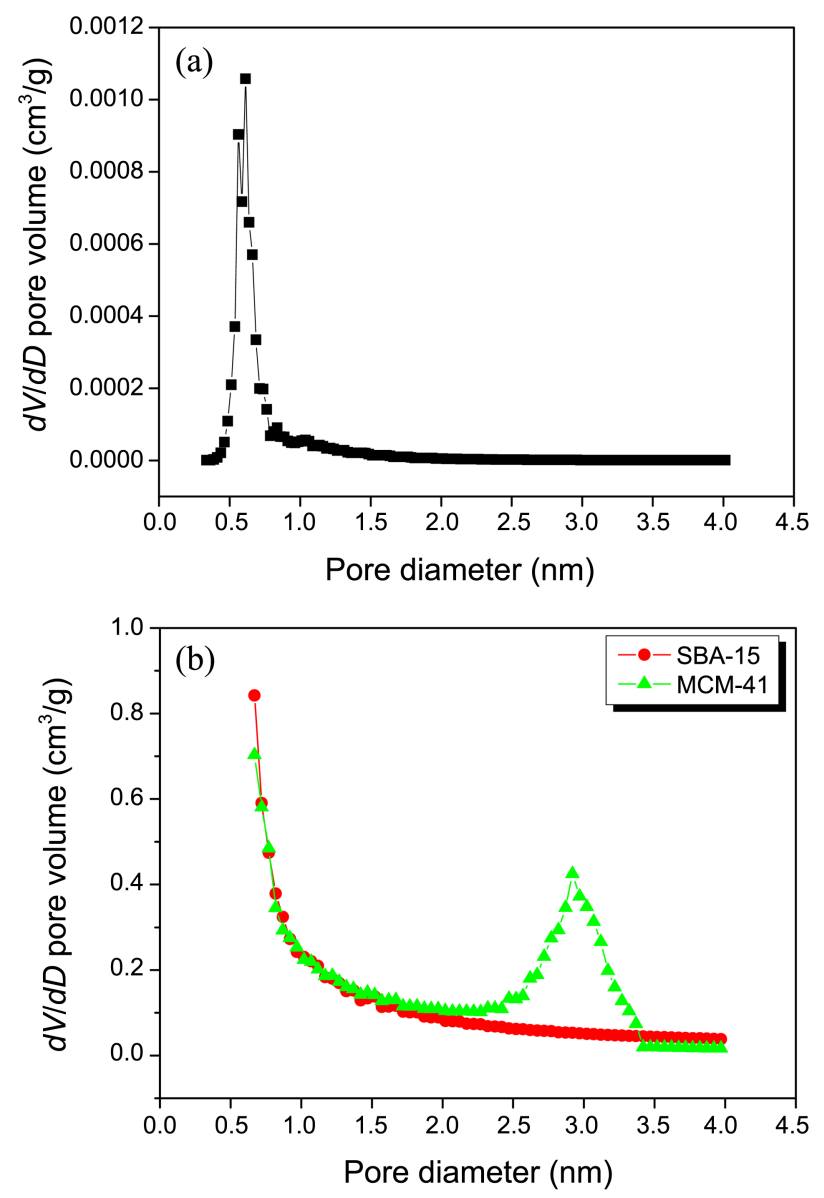

Figure 6. HK pore size distribution of (a) ACs, (b) SBA-15 and MCM-41.

and that the SBA-15 and MCM-41 both have a mesopore structure. These results are in agreement with those previously reported in the literature..$^{23,24}$

Elemental Mercury Adsorption. Figure 7 shows the mercury vapor adsorption of the ACs, SBA-15 and MCM41. All tests were conducted at $70{ }^{\circ} \mathrm{C}$ for $1 \mathrm{~h}$ in the elemental mercury adsorption apparatus. Normally, gas adsorption depends strongly on the specific surface area and pore 


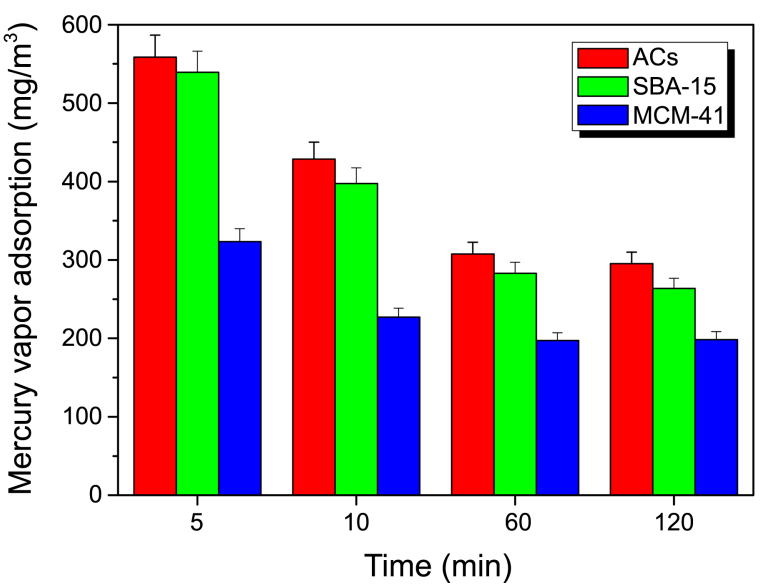

Figure 7. Elemental mercury adsorption of ACs, SBA-15 and MCM-41.

volume of the adsorbents. As shown in Table 1, The ACs showed high elemental vapor adsorption of $295.2 \mu \mathrm{g} / \mathrm{m}^{3}$, thus showing higher elemental vapor adsorption than the other samples (SBA-15: $263.6 \mu \mathrm{g} / \mathrm{m}^{3}$, MCM-41: $198.5 \mu \mathrm{g} /$ $\mathrm{m}^{3}$ ) due to the absolutely higher specific surface area and micro-/mesopore ratio.

Meanwhile, the specific surface areas of the SBA-15 and MCM-41 were 893.8 and 893.0, respectively. However, the mercury vapor adsorption was higher in the SBA-15. According to the fraction of the micropore volume, SBA-15 was higher than MCM-41. This shows that the micropore volume plays a role in determining the mercury vapor adsorption.

In conclusion, the optimal materials for mercury vapor adsorption possess the following attributes: (1) a high-specific surface area, and (2) a high-micropore fraction.

\section{Conclusions}

In this study, various pore structures were prepared to optimize their pore structure for mercury vapor adsorption. Micropore materials (ACs) showed high elemental vapor adsorption of $295.2 \mu \mathrm{g} / \mathrm{m}^{3}$. However, comparing to two types of mesopore materials (SBA-15 and MCM-41), the mercury vapor adsorption was higher in SBA-15 as SBA-15 has a higher micropore volume fraction than MCM-41.We can conclude this work by stating that mercury vapor adsorptions rates can be optimized in terms of the specific surface area and micropore fraction.

Acknowledgments. This subject is supported by Korea Ministry of Environment as "The Eco-technopia 21 Project".

\section{References}

1. Darbha, G. K.; Singh, A. K.; Rai, U. S.; Yu, E.; Yu, H.; Yu, H.; Ray, P. C. J. Am. Chem. Soc. 2008, 130, 8038.

2. Pavlish, J. H.; Hamre, L. L.; Zhuang, Y. Fuel 2010, 89, 838.

3. Ji, H.; Kim, J.; Yoo, J. W.; Lee, H. S.; Park, K. M.; Kang, Y. Bull. Korean Chem. Soc. 2010, 31, 1371.

4. ShamsiJazeyi, H.; Kaghazchi, T. J. Ind. Eng. Chem. 2010, 16, 852.

5. Kruk, M.; Jaroniec, M. Chem. Mater. 2001, 13, 3169.

6. Kim, D. J.; Kim, J. W.; Choung, S. J.; Kang, M. J. Ind. Eng. Chem. 2011, 14, 308

7. Jaroniec, M.; Solovyov, L. A. Chem. Commun. 2006, 2242.

8. Lee, B. I.; Bae, D.; Kang, J. K.; Kim, H.; Byeon, S. H. Bull. Korean Chem. Soc. 2009, 30, 1701.

9. Mattsson, S.; Nyström, C. Eur. J. Pharm. Biopharm. 2001, 52, 237.

10. Park, S. J.; Jang, Y. S.; Shim, J. W.; Ryu, S. K. J. Colloid Interface Sci. 2003, 260, 259.

11. Bradley, R. H. Carbon 1991, 29, 893.

12. Bagreev, A.; Bashkova, S.; Bandosz, T. J. Langmuir 2002, 18, 1257.

13. Kim, J. M.; Kwak, J. H.; Jun, S.; Ryoo, R. J. Phys. Chem. 1995, 99, 16742.

14. Park, S. J.; Lee, S. Y. J. Colloid Interface Sci. 2010, 346, 194.

15. Brunauer, S.; Emmett, P. H.; Teller, E. J. Am. Chem. Soc. 1938, $60,309$.

16. Kim, B. J.; Lee. Y. S.; Park, S. J. J. Colloid Interface Sci. 2007, 306, 454.

17. Dubinin, M. M.; Plavnik, G. M. Carbon 1968, 6, 183.

18. Kresge, C. T.; Leonowicz, M. E.; Roth, W. J.; Vartuli, J. C.; Beck, J. S. Nature 1992, 359, 710.

19. Han, O. H.; Bae, Y. K.; Jeong, S. Y. Bull. Korean Chem. Soc. 2008, 29, 405 .

20. Gregg, S. J.; Sing, K. S. W. Adsorption, Surface Area and Porosity; Academic Press: New York, 1982.

21. Meng, L. Y.; Cho, K. S.; Park, S. J. Carbon lett. 2010, 11, 34.

22. Sing, K. S. W.; Everett, D. H.; Haul, R. A. W.; Moscou, L.; Pierotti, R. A.; Rouquérol, J.; Siemieniewska, T. Pure Appl. Chem. 1985, $57,603$.

23. Ciesla, U.; Schüth, F. Microporous Mesoporous Mater. 1999, 27, 131.

24. Gucbilmez, T.; Dogu, T.; Balci, S. Catal. Today 2005, 100, 473. 